\title{
Tapping into the Intellectual Capital at the University
}

\author{
Mary Griffith \\ Faculty Modern Languages, University of Málaga, Spain
}

Copyright $\bigcirc 2017$ by authors, all rights reserved. Authors agree that this article remains permanently open access under the terms of the Creative Commons Attribution License 4.0 International License

\begin{abstract}
Content and Language Integrated Learning (CLIL) is as full of challenges as it is of possibilities. We will explore the challenges while seeking realistic solutions as eight Computer Science professors teach their subjects through English for the first time. We hope to gain insights into the bilingual classroom at the university level where teacher training can aid in professional development. Kevin Haines (2017) has posed the question about policies, principles and practice in bilingual settings, suggesting that we still need to address the challenging question: 'who will support the teachers?' In this paper we will observe problems and solutions to bilingual teaching from the ethnographic point of view of action research. We hold that research in education must make the move toward a more qualitative assessment. As researchers, perhaps we need to describe less and $d o$ more by putting our research into action.
\end{abstract}

Keywords CLIL/EMI, Computer Science, Teacher Training, Professional Development, Research in Action

\section{Introduction}

Content and Language Integrated Learning (CLIL) or English Medium Instruction (EMI) are the new catch phrases of internationalization in universities across Europe. However, one of the inherent problems for multilingual implementation is how to combine content specialization with foreign language teaching specialization, we must explore content professors' more practical concerns when facing bilingual instruction. In fact, if we truly plan to create a plurilingual university we must actively seek out content professors who are largely uncomfortable with teaching through a foreign language. They need both orientation as well as assessment and collaborative training programmes may indeed highlight the multiple differences between teaching language and teaching content.

The term CLIL was adopted in 1994 (Marsh, Maljers \& Hartiala, 2001) and rapidly considered successful and enriching to learning. CLIL became an educational approach of convergence; in fact, converging language learning with content learning is "where CLIL breaks new ground" (Coyle, Hood \& Marsh, 2010, p. 4). But now this term is subdividing into more specific areas, making it necessary to clarify terminology.

Smit and Dafouz (2012) have distinguished between the following terms: "English Medium teaching (Coleman, 2006), EMI (English Medium Instruction) (Hellekjaer, 2012), CLIL (Marsh, 2006: Dalton Puffer, Smit \& Nikula, 2010b) and ICLHE (Integrating Content and Language in Higher education (Wilkinson \& Zegers, 2007).” p. 2). What we have observed is that the debate now seems to be surging around the terms CLIL and EMI, in particular with regard to higher education (see Airey, 2012; Morgado \& Coehlo, 2012) where English seems to be pushing ahead of other languages and where form issues oftentimes go unbridled. We have observed that the perfectly balanced CLIL model seems to work better with children because their language and cognitive needs are developing simultaneously, making it more natural to combine language with content, while the content approach or EMI seems to be the preference for higher education. In this study, we will use the umbrella term CLIL while focusing on the more specific needs of higher education taught through English.

In higher education, CLIL research can be divided into three main perspectives: First, classroom discourse, next, teacher cognition and lastly plurilingual policies. Smit and Dafouz (2012) report:

To date as most of the published research confirms, the driving force to integrate language and content in higher education is clearly one sided and comes mainly from linguists, language teachers and teacher educators. In contrast politicians, university authorities, administrators as well as part of the lecturing staff (ie. content specialists) have initially engaged in this new scenario by embracing top-down internationalization plan alongside a chance for professional and academic development; a scenario wherein pedagogical concerns and more specifically language learning matters are usually of secondary importance. (p. 8)

In contrast, this CLIL professor support network aims to 
put pedagogical concerns and language learning matters at the forefront. One can never fully separate learning from teaching, but we feel the instructional side to CLIL in practice at the higher educational level might be of great interest to professors willing to engage in this new academic scenario. In fact, this paper addresses Kevin Haines' (2017) question: "Who will support the teachers."

Without the practical element, professional development in education is detached from the setting and the real challenges professors face every day. This study explored the question of whether participatory action research can provide meaningful experiences that add to good teaching practice in the implementation of a bilingual program.

\subsection{Research Context and Aims}

Problems with the plurilingual research agenda include the difficulties in reaching conclusions given the variables of the contexts involved. In this study, we struggled to find one direction for our research given the wide range of research themes now emerging. Many researchers have enriched our understanding of CLIL/EMI offering timely contributions. Morgado and Coehlo (2012) have created an interesting comparative study between CLIL and EMI. Gajo (2007) has discussed content-subject competence moving away from the traditional linguistic focus on form. Llinares, Dafouz and Whittaker (2007) have dealt with content-subject methodology and discourse genres by contemplating how teaching through a second language differs; Lorenzo (2008) has discussed how teachers adapt texts with rediscursification; Clegg (2006) has brought compensation strategies into the discussion to explore what professors can do to compensate the inherent challenges to teaching-learning through a second language.

As CLIL balances a language focus with a content focus, it continues to be complex, particularly in practice. Specifically related to CLIL, other authors have pointed out this dichotomy between form focus and content focus and offer another assessment distinguishing between the strong and the weak versions of CLIL suggesting the many possible ways to approach instruction through a second language.

The "strong" or "content-driven" approach is for some writers the only possibility. In a strong approach, the syllabus is dependent solely on the specific subject-content. There is no language grading, and language is introduced as and when it is necessary for the topics to be studied and the tasks to be performed, in a "just in time" approach. The "weak" or language-driven" approach, on the other hand, will take account of more traditional language grading and modify content and tasks to suit the current language level. (Coyle et al. 2010, p. 1)

Outside language areas, what we observe, is that you will be unable to "connect" with content teachers at the university level, if you do not approach CLIL from the content driven approach. One of the undeniable limitations of CLIL research is that one of the main participants, the content professor is oftentimes excluded from the discussion. So while practice is informed by the underlying linguistic theories, how can we make this more explicit for content professors?

We choose to approach our CLIL teacher development from a didactic point of view by including content professors in our research proposal. Undoubtedly it will be the key to include in the discussion how CLIL instruction can vary and how teachers can compensate. We aim to bring these compensation strategies into the Computer Science classroom by guiding teacher performance. What is essential is for professors to see how to use language support strategies with their own contents, with their own students and with their own teaching style.

This paper is dedicated to professors outside language areas approaching CLIL in an aim to orientate and assess. It is also intended to explore points of view not usually explored in traditional research. Methodology has been described as a series of choices researchers make to gather information about research questions. In its broadest definition methodology is not a formula, but rather a set of practices. We will present an overview of an action research project to help professors teach through English, which we have called "developing the CLIL eye."

\section{Method}

Action research is known by many other names, including participatory research, collaborative inquiry, action learning, among others, but put simply, action research is 'learning by doing.' In essence what happens is that a group of people identify a problem, do something to solve it, assess how successful their efforts were, and if not satisfied, try again. Gilmore, et al. (1986) have provided a more academic definition:

Action research...aims to contribute both to the practical concerns of people in an immediate problematic situation and to further the goals of social science simultaneously. Thus, there is a dual commitment in action research to study a system and concurrently to collaborate with members of the system in changing it in what is together regarded as a desirable direction. Accomplishing this twin goal requires the active collaboration of researcher and client, and thus it stresses the importance of co-learning as a primary aspect of the research process. (p. 161)

It differs from other research in its focus. It differs in that it is more like progressive problem solving, constantly undergoing revision and moving forward. But above all, action research is practical and relevant to the participants.

Although some would refer to all action research as lacking scientific rigor, we purposefully opt for this 
method. Donald Schön (1987) in his book Educating the reflective Practitioner refers to the difficulties of this bottom-up approach stating:

[I]n the varied topography of professional practice, there is a high, hard ground overlooking a swamp. On the high ground, manageable problems lend themselves to solution through the application of research-based theory and technique. In the swampy lowland, messy, confusing problems defy technical solution. The irony of this situation is that the problems of the high ground tend to be relatively unimportant to ... society at large ..., while in the swamp lie the problems of greatest human concern. ( $p$ 3)

So as we enter our "swamp" we begin to fully understand compensation, for CLIL is an imperfect model to begin with. We move beyond description, toward action, but inevitably make many mistakes along the way. But this does not imply lack of rigor. We move directly into the classroom to begin to discuss CLIL from the content teacher's point of view. We begin by removing the word perfection from our initial goal in search of greater relevance to the participants involved.

Thus, the project began with the proposal to orientate, with the proposal to capacitate, with the proposal to help professors teach though a second language in a purposeful search for quality instruction. Reason and Bradbury (2001) expand: "It's about working towards practical outcomes, and also about creating new forms of understanding." (p.10) The understanding emerges through reflection in action and the interaction of all the participants. Other authors have called this "facilitation" (Heron, 1989) or "unlocking human potential" (Van Nieuwerburgh, 2011) or simply "knowledge integration" (Goffen \& Koners, 2011). We understand this process as tapping into the intellectual capital at our university.

\subsection{Participants and Roles}

The multiple perspectives of this project can be seen by the active participation of all the participants and the way they construct a meaningful reality out of their interactions. Let us briefly identify the people and their roles.

The researcher/CLIL coordinator fulfills an interchanging role of participant observer, evaluator, motivator, as well as language specialist. We note that her lack of computer science background while initially could be construed as an impediment became an advantage as she continually forced instructors to get to the essence of their contents. At the same time, by approaching this project she has strived to bring language learning theory into practice; she has become an accomplice to practice.

Eight Computer Science professors who taught in nine subjects had equally varied roles. They could be seen as participant observers, as trainees, as well as motivators. The group is comprised of experienced Spanish professors who had never previously taught their subjects through English (L2). We note that the success of their first experience of teaching through English was largely their own reflective exercise of thinking about how they teach, about what they transmit and about how their students learn. They began the project with varying degrees of reluctance, but also an admirable desire to improve their own teaching practice. They also began the project with no idea of how to put CLIL into practice. As the academic year progressed, they found the theories became a reality in their classrooms. So, they too become accomplicesaccomplices to theory as their own practice became more informed.

Students include both freshman and sophomores who voluntarily took these courses in English. The professors' initial concerns of students' lack of foreign language proficiency, proved in practice to be unfounded. Students had very little difficulty with the foreign language and the teachers were pleasantly surprised. In a post evaluation survey, students cited the complexity of the contents as the most challenging aspect and never the foreign language itself. Their evaluation results speak for themselves. Proper assimilation of course contents has been pointedly achieved at the same or superior to the classes taught in first language (L1), but their true contribution to this study is found in the open comments about each subject as well as in their classroom interaction.

\subsection{Research Questions}

The initial proposal for the in-service training came from a practical reasoning. How can the university become plurilingual without the entire faculty embracing this option? Each research question has been addressed and the whole project has been assessed from multiple perspectives. The data collection process was ongoing throughout one academic year.

Most empirical research tries to make sense of the world using ideal models. However we have embraced the complex and unrepeatable classroom experience as an extremely valid and useful tool for teacher training.

Rejecting ideal models of perfect bilingualism does not imply having no objectives. What we question is the feasibility of these objectives. The essence of the ideal models is that they do not exist in the real world tending to maintain as constants what in reality are ever changing and interacting variables. Consequently, "true science" tends to measure the deviation of our reality with models that do not, or cannot, exist. While this may work for some fields, it is not as applicable to research in education for, in effect, educational success resides in the interaction of those ever changing variables. Educational success resides in the movement towards the ideal, not in the deviation from this ideal model. Bilingual teaching moves towards bilingualism but cannot be measured by the perfect bilingual model. Instead, the ultimate CLIL objective is functionality in foreign language together with content 
assimilation; and this is how teachers will be assessed.

In our intention to discover the intellectual capital of our university, we place professors' needs at the center of the discussion for this in-service training; we invited them to share in the creating of inquiry. They formed an integrated part of the research process and enriched many of the discussions about their professional practice. What we have seen is that knowledge integration begins with areas of practice and expertise that can only be described as tacit knowledge. The research questions are shown in Table 1 and are connected to the data collection method and findings which will be developed in the next section.

Table 1. Developing the "CLIL eye" using research questions as the motor to inquiry

\begin{tabular}{|c|c|}
\hline Data & Inquiry \\
\hline Diagnostic survey & 1. What are the challenges? \\
\hline $\begin{array}{l}\text { Compensation in } \\
\text { materials }\end{array}$ & $\begin{array}{l}\text { 2. How do professors compensate CLIL } \\
\text { complexity? }\end{array}$ \\
\hline L2 error analysis & 3. What are the most common L2 errors? \\
\hline Student interaction & 4. Do students interact? \\
\hline Student results & 5. How do L2 students results compare with L1? \\
\hline Student survey & 6. What do students think about the experience? \\
\hline $\begin{array}{l}\text { Professor participant } \\
\text { survey }\end{array}$ & $\begin{array}{l}\text { 7. What do professor participants think about } \\
\text { network? }\end{array}$ \\
\hline
\end{tabular}

\section{Findings}

We will define quality implementation using teacher foreign language performance, materials creation, student interaction, student results, and student opinion. By maintaining our original goal of knowledge integration, professors have taken part and been privy to all data collected in order to achieve the ultimate goal of professional development. The objective of all data collection is to better understand CLIL in practice at the university and to adapt our in service training in order to create a greater awareness of how instruction through a second language can be supported specifically in the Computer Science department. The following results will be structured according to the original research questions which were developed after the initial diagnostic survey.

\section{Results Diagnostic Survey: What are the Challenges?}

The diagnostic stage included a pilot study and several diagnostic surveys. The diagnostic stage is designed to bring the theories closer to real practice but within a determinate situation. In order to do so, the researcher developed a survey to see where the biggest challenges lay. These challenges ranged from concerns about material preparation, to evaluation as well as individual concerns about foreign language performance for students as well as for instructors. Once the challenges were identified, the group met as a whole and drew up an action plan for the academic year. The goal of this plan was to move from general to specific goals within the realistic frame of their classrooms and the specific assessment will be seen in the data collected.

\section{Results in Materials: How Do Professors Compensate Instruction Through a Second Language?}

During implementation, the plan was put into action and a procedure for training was developed. The main aspects during implementation consisted of material correction, classroom observation as well as group meetings. İn this section, we do not have the space to elaborate fully, but some examples will illustrate the implementation phase. Much of the coordinator's feedback was more about good teaching than specifically about CLIL. These strategies have been loosely categorized as compensation strategies in materials and there were a many examples that drew our attention. For instance, CLIL should be more visual, but professors, uncomfortable about the language required, tended to overload their material presentations with text. Unfortunately, students are more challenged by this overloaded format. In fact, one student thought the word 'Chomsky' was just another word he did not know in English. So compensation in this case was simple: The teacher adjusted his material to include an image that provided instant clarification. Compensation also includes lexical support. Only one professor systematically began each unit with a lexical focus of terminology in both English and Spanish; and in these glossaries, he clearly anticipated terminology needs in both languages. And as a final example, the coordinator closely examined materials. In Figs. 1 and 2, we observe the transition from the original to the revised. (For more examples on materials see Griffith, ACLES, 2017, forthcoming; Griffith \& Lechuga, ICLEL, 2017 this issue) What is salient in the materials revised is that structural support, reducing and highlighting seemed to be the most common strategies.

- Structure: Static vs. Dynamic
Programming languages can support a process
structure:
- Static: the number of processes during
execution is defined in compile time
- Dynamic: processes can be created
dynamically; Thus the number of processes is
known during execution time
- Despite ef using a dynamic structure,
the maximum number of processes is limited
by the computer memory /architecture

Figure 1. Lexical overload, Programming Concurrent Systems, 2011 




Figure 2. Simplification Proposal, Material Revision, professor support network, University of Málaga

These figures show how lexical points are highlighted, how language is simplified and the visual presentation is in an explicit comparative structure from left to right. No content has been lost rather the essential contents have been focused. Each professor received one full unit revised and then could put into practice what we presented theoretically as language support strategies, or simply stated, clarification strategies.

The data produced by the observation feedback is immense and challenging to organize into categories. However, the categories are not predetermined; instead, they surge out of practice. Professors found the comments related their own specific practice to the compensation strategies highly relevant to their own professional development. What we found was that by systematically demonstrating how language could be supported, how contents could be better structured, how instruction in the classroom could be made more interactive, professors began to see how their bilingual classrooms were not only didactically sound, but the strategies could be carried over into their normal routines of content teaching. The good practices in materials created and later illustrated in the group meetings proved to be extremely effective for peer learning moments.

\section{Results Frequent Errors in Language Performance}

We saw in the previous section how good practice was publicly shared. In contrast, errors in performance were presented privately, or, if more common, these same errors were presented anonymously. It has been our intention to focus the practicum on teaching methods and not on linguistic errors. Consequently, we have chosen to approach issues of form focus sparingly in our comments on teachers' errors deciding that this was never to be the sole focus of the in service training. Nonetheless, professors valued the corrections of usage in English, perhaps much more than the researcher intended. The class sessions were recorded allowing for a complete replay of the sessions and each teacher received a private correction of the sessions with the errors in L2 performance. Some examples can be seen in Figure 3. Pronunciation was an issue, but never to the point of preventing communication. Vowel quality was challenging as was the target tonic stress patterns. Professors would say estor instead of store, lunch instead of launch, pee instead of pi, impotent instead of important to mention just a few of the higher frequency errors. More significantly, we observed that improper marking of stress patterns led to misinterpretations of the negation. In order to compensate, we asked these teachers to be more emphatic with the negation or to provide a visual clue in their material. And finally, syntactically, there was some confusion surrounded the usage of embedded questions and interrogative syntax in general.

\section{MOST FREQUENT ERRORS IN L2}

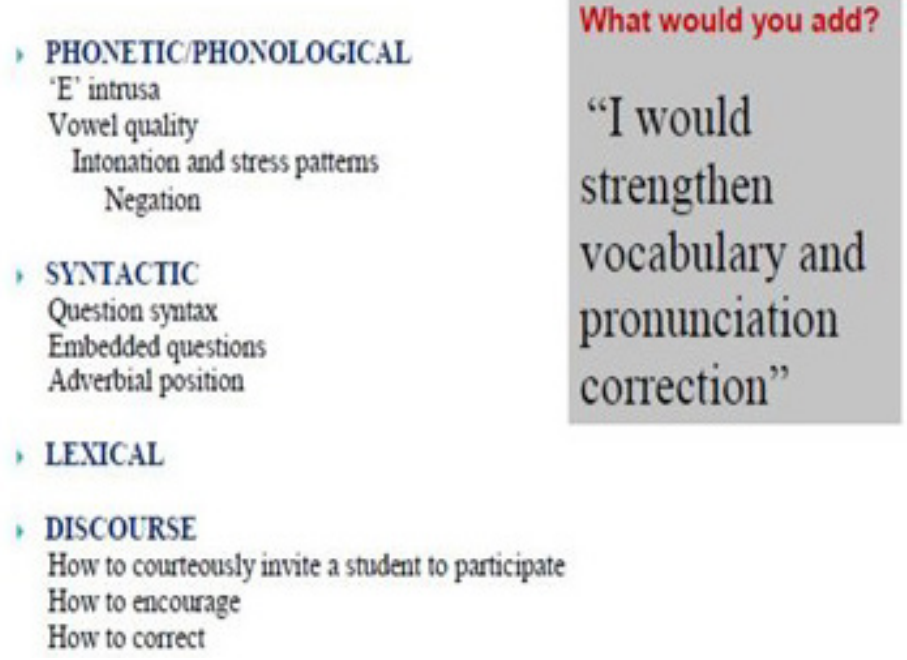

Figure 3. Frequent errors in foreign language performance during instruction, University of Málaga, 2011-2012 
Many teachers self-corrected these errors in the second observation. Consequently, what was interesting was not the error in itself, but in effect, how teachers were able to learn from their own errors. And although, the coordinator did not want to turn the Practicum into an improvised English class; the professors considered this correction as vital to the project and in their final survey even suggested that this aspect be expanded proposing "I would strengthen vocabulary and pronunciation correction." However, a more global linguistic analysis has shown that not vocabulary, but rather discourse that professors should be tuned into. This linguistic data and subsequent error analysis will not be dealt with in this paper and is as of yet, unpublished.

34 hours of class performance have been observed creating an extremely rich data base for both didactic and linguistic analysis. However, in reference to teachers' foreign language proficiency, we would like to specifically point out that students were well aware which professors had the highest level of English. They were also aware of who transmitted most effectively the course contents. Interestingly enough, the teachers with the best English were not necessarily the best content teachers. CLIL is much more about proper teaching than about proper foreign language use. This in itself was a statement of liberation for these teachers. In fact, results indicate that the professor with weaker English tended to modulate his voice more, ask more effective follow up questions, summarize with greater frequency and, as we will see in the next section, also effectively inspire more student interaction.

\section{Results Student Interaction}

We have included interaction in our own assessment, but rather than analyzing the discourse of the interactions, we have quantified them and associated them with what teachers do to encourage more and better interactions. Professors have seen this correlated specifically with what they do or say in the sessions. In this article, we will highlight the multiple variables that impact on student performance in a comparative assessment. We found the cross comparison useful for the participants and interaction was correlated with the multiple variables (teacher's style, content, student response among others). These can be measured by the overall student interactions seen in Figure 4. In one two hour session the maximum number of interactions by students was eighty-one, while the minimum was six. In this chart, nothing is said about the quality of the interactions, but seen globally they offer some interesting cross comparative data. In seven of the nine subjects the sophomore student group remained fairly constant, while the two remaining subjects from freshman groups each had different student For example in the Algorithm class there is a big difference between the two sessions observed associated with a theoretical class (seventeen interactions) as opposed to a practical one (eighty interactions)., while in both Data Bases as well as in Data Structures, the student interactions were similar in all sessions observed in accordance with the more practical focus of these subjects. We see the more theoretical subject (Automatas) having less interactions, than the other subjects even though the Sophomore student group remained constant. We see a great improvement in the first year interactions if we compare two programming courses: Fundamentals with Objects offered in different semesters. We see how the same professor and the same student group in a different subject had different results in interactions if we compare Data Bases with Concurrent Systems, suggesting that perhaps the contents themselves play a role in student interaction. We also see the lowest numbers in classes that were the absolute first class in Fundamentals or the absolute last class as in automatas, suggesting that the sequence of classes might also play a role. By presenting this information about real practice, teachers could see the range of "accepted" behavior in CLIL classes while at the same time reflecting on ways to improve their own professional practice. Perhaps it is gratifying to conclude that although not every class is perfect, every class can be improved. And, that the variables of content, student motivation and teacher performance all play a part. Foreign language teachers seem to measure quality with interaction, but we have seen that outside language teaching, quality must be measured according to the specific context. 


\title{
STUDENT INTERACTION
}

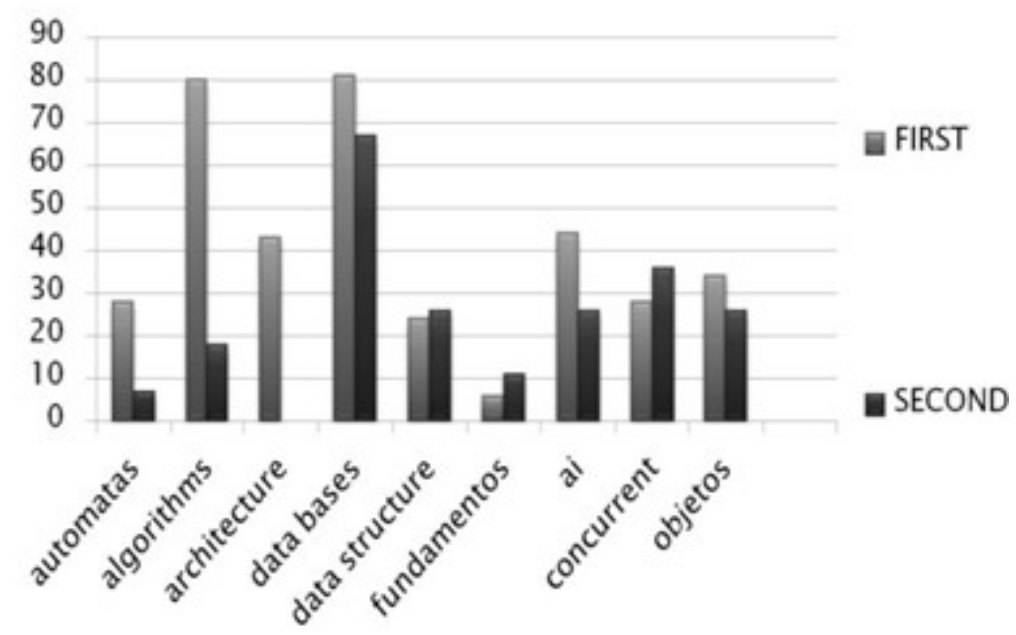

Figure 4. Student interactions in CLIL Computer Science, 2011-2012

\section{Student Results as Compared with Spanish (First Language) Groups}

\author{
Content classes in English: How do first language results compare with second \\ language results in 9 computer science classes?
}

L1 GLOBAL RESULTS STUDENTS

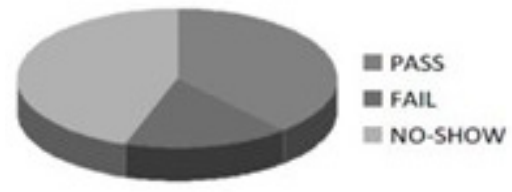

L2 GLOBAL RESULTS STUDENTS

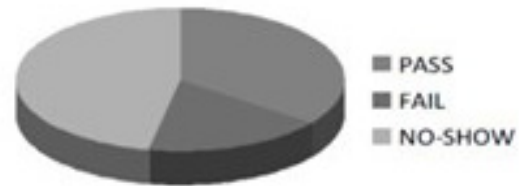

Figure 5. Student comparative results in 9 subjects offered in Spanish (L1) and English(L2), University of Málaga, 2011-2012

This comparison between the Spanish group (L1) and the English group (L2) was created in response to a petition from the department head. All students in CLIL classes were the same or superior in final evaluation results. Here we should be wary of jumping to conclusions about using this data as part of professor performance assessment. The CLIL groups were much smaller, allowing for more individualized attention as well as more active manipulation of contents during class sessions. In addition, the students who opted for these CLIL classes have consistently higher average entrance scores as assessed by the Spanish "selectividad," a university access exam that all students must complete. Consequently, if they began the course already with an advantage, perhaps it is unwise to claim this as part of the CLIL qualitative assessment. In Fig. 5 the comparison of the 9 subjects offered in both English and Spanish shows the great degree of internal consistency across all subjects.

Let it suffice to say that students performed as well in the CLIL classes and their own foreign language proficiency was never seen as an impediment to content assimilation.
Our intention was never to prove that these CLIL courses were better, but rather simply, that students could learn directly through English and in turn, be assessed through English. For these two aspects were included in the original action plan. What we do strongly recommend is that all bilingual classes be assessed comparatively in content assimilation with monolingual courses. A more qualitative assessment will be presented in the next section discussing student response to bilingual instruction.

\section{Student Survey}

Forty two students participated in the survey designed to explore the students' perspective of this CLIL experience. In this section, we will present the quantifiable data together with the qualitative in a highly summarized form. An essential part of the Practicum offered professor participants this information at the close of the academic year. In Figs. 6 and 7, we see that students gave their professors an extremely positive evaluation as associated with their own learning. 
Students' assessment of English Medium Instruction in Computer Science

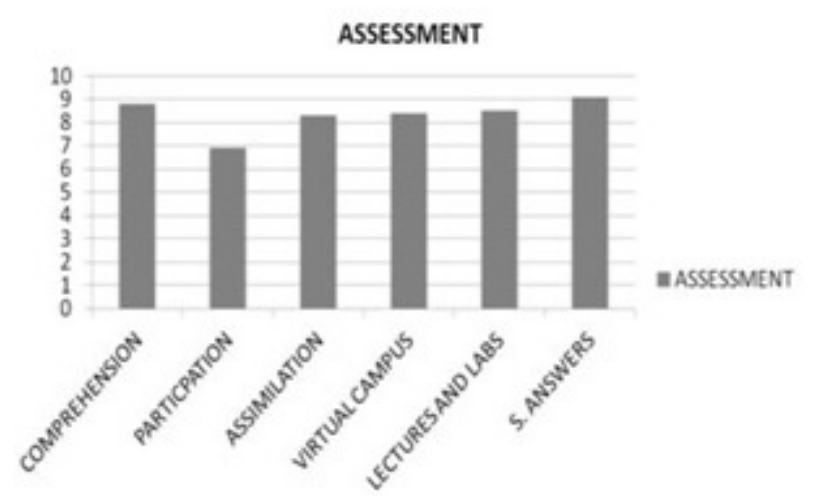

Figure 6. Student survey, professor support network, University of Málaga, 2012

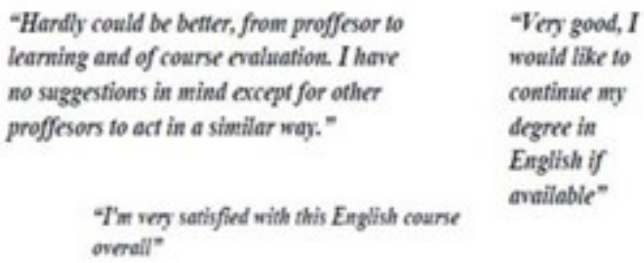

"I feel things are being inproved step by steg. Well done"

\section{"I enjoyed it quite mach and I think I} learned a lot $^{2}$

Figure 7. Student response to instruction in a second language in Computer Science, University of Málaga, 2012

Students felt their comprehension to be well above eight out of a possible ten, their participation at just under seven, their assimilation at over eight, the material on the virtual campus as well as the material presented during lectures scored also at above eight, and finally students' perception of their ability to be evaluated in a second language at a surprising nine. Students also consistently reported that they would repeat the experience and recommend it to other students. The significance of these comments was uplifting for teachers who oftentimes never get a chance to explore what students think about their performance. This can be seen in their open comments as well both the positive as well as the negative.

Of course not all the comments were positive. What is significant in the negative comments is how specific they are. Students know how they want to learn. They want more opportunities to participate, not less. We note how in these three examples students make explicit reference to form focus.

[1]. "The evaluation in the language should be carried out with a bit more precision regarding with the level of English, and if the required student is progressing with the language or not"
[2]. "Well , I think that the laboratories classes must be in English too, on that way we could get used to with the subject in English"

[3]. "Maybe more incentives to speak English during the class"

Typically, university professors receive the results of student surveys only in quantifiable terms. These more qualitative results proved to be enlightening to each professor's performance. Indeed, the participatory action research approach allowed professors to step back from their professional practice and reflect. All the results were presented globally at the closing session of the academic year. The group experience was valued considerably by the teachers who felt free to still do things their own way while improving techniques. In effect, they learnt from each other as much as they learnt from the coordinator.

\section{Conclusions and Final Remarks}

When research becomes research about people, it involves a unique outlook. In the CLIL context, there are instructors and students; there are linguists and researchers; there are plurilingual administrators. The European Higher Education Area has decided that plurilingualism is part of what it means to be European, but decisions from the top down mean nothing without the commitment of university professors. So what exactly is the difference between a decision and a commitment? Simply stated, decisions are intentions, while commitments lead to actions.

This study has dealt with commitment through the professional development of CLIL professors at the university level. Some universities find themselves in what Donald Schön (1987) calls a "squeeze-play": An educational institution in which educational policy plays a small role. "In the normative curriculum, a practicum comes last, almost as an afterthought. (pp. 310-311)" Very little has been written about professional development at this tertiary level, but many of the issues related to action research developed in other academic settings apply. Nevertheless, there are some specific considerations related to professionals in higher education, their needs and their expectations.

Without the practical element, professional development in education is detached from the setting and the real challenges professors face every day. This study explored the question of whether participatory action research can provide meaningful experiences that add to good teaching practice in the implementation of a bilingual program. Action research as methodology involves a paradigm of praxis in circumstances that require flexibility, the involvement of the people in the research as well as the commitment to change. The final assessment is the professor participant survey that valued the in service training as a unique opportunity to reflect on their teaching practice. The results can be seen in Figure 8 . 


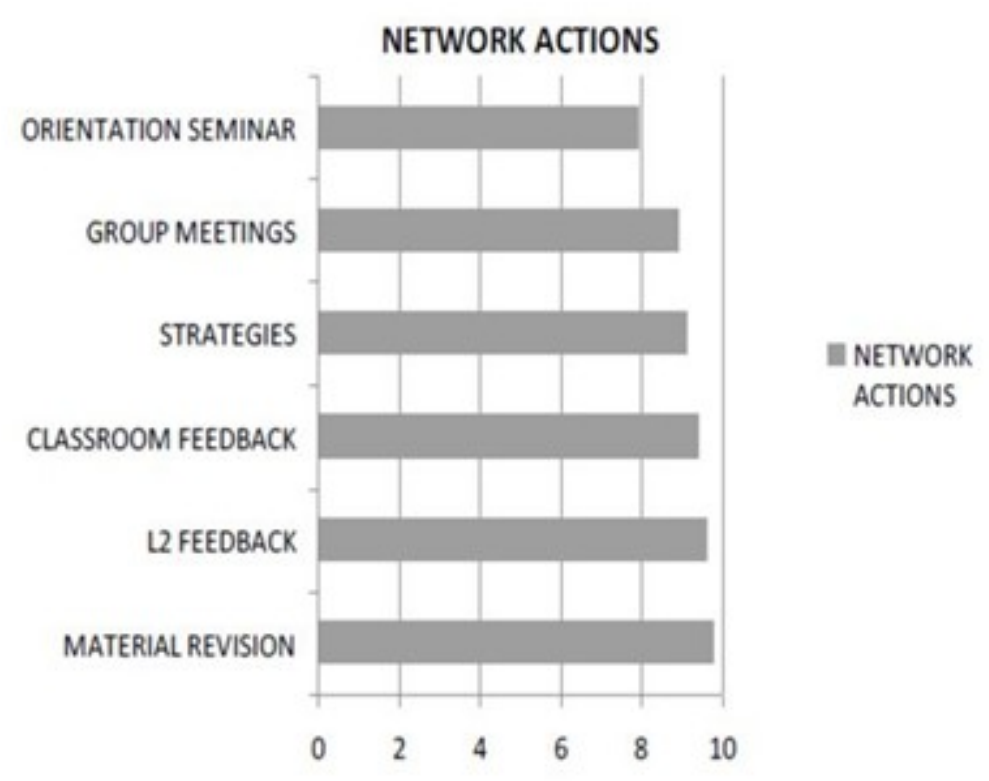

Figure 8. Professors rate participation in professor support network as relevant

By far the most valued action was with material revision considered as valuable and relevant followed by specific comments on language performance and classroom feedback. Many of the results have been seen in the evidence just elaborated; however, these final remarks aim to move beyond results to implications. We will dedicate this last section to the most difficult questions any researcher faces about relevance for the stakeholders and CLIL implementation.

So what happened next? In the Computer Science department the following year three more subjects through English were added, professor participants continued to be supported for the next four years; and after four years the department saw a fourfold increase in foreign exchange students. At the University of Málaga, the training project expanded into the Tourism faculty, the Economics faculty, the Education faculty and now in this year we are collaborating in the Law faculty. The most salient point is that the success of plurilingual implementation does not reside in any one decision by plurilingual planners somewhere in Europe, but rather by the commitment to action by university professors within the specific context of their departments, their contents and their students. Our own willingness to adapt to each context has been our personal commitment to developing the CLIL eye and the data collected has been the contribution of our action research project.

The ultimate goal is content professors' commitment to plurilingual implementation. As linguists we find it easy to believe in bilingualism, but content professors find themselves uncomfortable in this new found role of language expert (Hynninen, 2012). We insist that, through a facilitative collaboration, this change can impact teaching practice in higher education. What this means is that content professors need to stop taking language for granted in their instruction; and language specialists must stop trying to convert all instructors into linguists. CLIL collaboration gives all involved a unique opportunity to learn from the other.

As a linguist inserted into a context of engineers, I have to admit I felt like a fish out of water "inserted" into these Computer Science classes. The implication is one of empathy. I can only imagine that is exactly how they feel when approaching CLIL for the first time. We understand this process as tapping into the intellectual capital at our university. Collaboration is sometimes accepting your role as a fish out of water and compensating accordingly for content teachers and for language specialists alike.

\section{REFERENCES}

[1] Airey, J. (2012). I don't teach language: The linguistic attitudes of physics lecturers in Sweden. In U. Smit and E. DaFouz (Eds.), AILA Review: Integrating Content and Language in Higher Education Amsterdam: John Benjamins Publishing Co. 25, 64-79.

[2] Barrios, E., and López-Gutierrez, A. (2016). English Medium Instruction in the Education Faculty of Málaga University: Students' profiles. In J. Domenech, et al, (Eds.) Second International Conference on Higher Education Advances (HEAD’16): Universitat Politécnica de Valencia, pp 236-243.

[3] Clegg, J. (2006). Providing Language support in CLIL. Retrieved April 4, 2012, from http://www.factworld.info/journal/issue06/f6-clegg.pdf

[4] Coyle, D. (2007). Content and Language Integrated Learning: Towards a Connected Research Agenda for CLIL Pedagogies. The International Journal of Bilingual Education and Bilingualism Vol. 10, No. 5, p.p. 545-562. 
[5] (2012). CLIL in Spain: Implementation, Results and Teacher Training (Forward). In D. Lasagabaster, CLIL in Spain: Implementation, Results and Teacher Training. Newcastle upon Tyne: Cambridge Scholars Publishing. p.6.

[6] Dalton Puffer, C. (2007). Empirical Perspectives on CLIL Classroom Discourse. Frankfort: Peter Lang.

[7] Gajo, L. (2007). Linguistic knowledge and subject knowledge: how does bilingualism contribute to subject development? The International Journal of Bilingual Education and Bilingualism, 10 (5), 563-581.

[8] Goffin, K. and Koners, U. (2011). Tacit Knowledge, Lessons Learnt, and New Product Development. Journal of Product innovation management INNOV, 28 (22), 300-318.

[9] Gilmore, T. J., Krantz, J., and Ramirez. R., (Fall, 1986). "Action Based Modes of Inquiry and the Host-Researcher Relationship." Consultation 5.3, p.p. 160-76

[10] Griffith, M. (2012a). "CLIL and the Plurilingual University: Orientation for the Reluctant Professor." In Propuestas de actividades y metodologías específicas para la mejora del bilingüismo en ingeniería, F. Manzano and A. García (Eds.). Almería: Universidad de Almería. pp. 27-49.

[11] Griffith, M. (2012b). Por qué enseñar en inglés y cómo: Apoyo a la docencia bilingüe ETS Informática. In III Jornadas sobre innovación docente y adaptación al espacio europeo de educación superior en las titulaciones técnicas. Grupo Docente Interdisciplinar de ETSI de Caminos, C, y P. (Ed.). Universidad de Granada. 249-254.

[12] Haines, K. (2017). "But who will support the teachers? Policy, Principles and practices for the support of English Medium Instruction at an International University: The Groningen experience." X Congreso da Asociación de Centros de Linguas no Ensino Superior (ACLES). University of Vigo. June 29 - July 1.

[13] Heron, J. (1989). The Facilitator's Handbook. London: Kogan Page.

[14] Hynninen, N. (2012). ICL at the micro level: L2 speakers taking on the role of language experts. In U. Smit, \& E. Dafouz (Eds.), AILA review Amsterdam: John Benjamin Publishing Company. (25), 48-63.

[15] Llinares, A., E. Dafouz, and R. Whittaker (2007) A linguistic analysis of compositions written by Spanish learners of social sciences in CLIL contexts. In D. Wolff \& D. Marsh (Eds.) Diverse Contexts Converging Goals. Content and Language Integrated Learning in Europe. Frankfurt: Peter Lang. 227-237.

[16] Long, M. (1991). Focus on form: A design feature in language teaching methodology. In K.de Bot, R. Ginsberg, and C. Kramsch (eds.), Foreign language research in cross-cultural perspective. Amsterdam: John Benjamins, 39-52.

[17] Lorenzo, F. A. (2008). "Instructional Discourse in bilingual settings. An empirical study of linguistic adjustments in content and language integrated learning." Language Learning Journal, (36) 1:21-33.

[18] Marsh, D. (2001). Content and Language Integrated Learning in Europe. The European Dimension. Jyvaskyla: Univsersity of Jyväskyla Press.

[19] Morgado, M., and Coelho, M. (2012). Higher education experiments; CLIL versus English as the medium instruction: differences, similarities and the lessons to learn for the Portuguese context. Five years of Bolonia: Upgrading or Downsizing Multilingualism. Braga: IV CERCLES Seminar. 1- Retrieved 28 August 2013 from issuu.com/...docs/margaridamorgado.margaridacoelho_1a.

[20] O'Brian, R. (1998). An Overview of the Methodological Approach of Action Research. Retrieved November 26,2012, from Faculty of Information Studies, University of Toronto: http://www.web.ca/robrien/papers/arfinal.html\# Toc26184 652

[21] Reason, P. and H. Bradbury (Eds.). (2001). The Handbook of Action Research. London: Sage Publications Ltd.

[22] Schön, D. A. (1987). Educating the Reflective Practitioner. San Francisco: Jossey-Bass Publishers.

[23] Smit, U., \& Dafouz, E. (2012). AILA Review: Integrating Content and Language in Higher Education Amsterdam: John Benjamins Publishing Co. (25).

[24] Swain, M. and S. Lapkin. (1998). "Interaction and Second Language Learning: Two Adolescent French Immersion Students Working Together." The Modern Language Journal. Vol. 82 Issue 3, p.p. 320-337. 